\title{
Simplified actor analysis for a case of developing renewable energy
}

\author{
V. E. Silin \\ The Ural Federal University named after the first President of Russia \\ B. N. Yeltsin, Russia
}

\begin{abstract}
Domestic fuels and renewables constitute less than $5 \%$ in the fuel balance of the Sverdlovsk region. However, the potential of renewables, including biomass, is higher. Some rural cottages and villages can be supplied with renewables placed around them. This paper describes the main actors in the field of developing renewable energy in the Sverdlovsk region, gives their classification (individual micro-scale consumers, joined small and mid-scale consumers, and other "actors") and presents their desired behaviour. As a conclusion, the paper offers one of the possible ways to force the development of renewable energy by using an "inverse infrastructure" approach.

Keywords: biomass, depressive rural, inverse infrastructure approach, municipal program, renewables.
\end{abstract}

\section{Introduction}

The Sverdlovsk region is heavily dependent of imported fuels [1]. Almost 50\% of fuel supplies are natural gas but the second part is coal. Both gas pipelines and railways have limited capacity. In addition, coal is ecologically unfriendly.

Domestic fuels (mainly - forest residues) constitute less than 5\% in fuel balance of region. However, the potential of renewables, including biomass, is higher. Some rural, cottages and cottage villages can be supplied with renewables placed around them. It might increase the level of life and sustainability of regional development. 


\section{Actors involved}

There are two potential groups of renewable energy consumers:

- Individual micro-scale consumers - end users of very low capacity engines and heat generators on renewables (less than $10 \mathrm{~kW}(\mathrm{e})$ or $20 \mathrm{~kW}(\mathrm{t})$, for example individual cottages or little shops with one or two small refrigerators);

- United small and mid-scale consumers - end users of small and medium capacity engines and heat generators on renewables (10-200 kW(e) or 20-500 kW(t), for example cottage villages, farms or apartment houses).

Consumers may be further classified depending on their prosperity level:

- "prosperous" consumers;

- "depressive" remote rural consumers.

Main features of consumers mentioned above are shown in the table 1 .

Table 1: Consumers of renewable energy.

\begin{tabular}{|l|l|l|}
\hline Parameter & \multicolumn{1}{|c|}{ "Prosperous" } & \multicolumn{1}{|c|}{ "Depressive" remote rural } \\
\hline $\begin{array}{l}\text { Examples of micro- } \\
\text { scale individuals }\end{array}$ & $\begin{array}{l}\text { Cottages, farms, individual } \\
\text { houses or little shops with one } \\
\text { or two small refrigerators }\end{array}$ & Remote owners \\
\hline $\begin{array}{l}\text { Examples of } \\
\text { united small and } \\
\text { mid-scale }\end{array}$ & $\begin{array}{l}\text { Cottage villages, apartment } \\
\text { houses }\end{array}$ & $\begin{array}{l}\text { Villages without gas and } \\
\text { power lines }\end{array}$ \\
\hline Public value & $\begin{array}{l}\text { Sustainable functioning and } \\
\text { development of environment }\end{array}$ & $\begin{array}{l}\text { More comfortable, safe and } \\
\text { modern life }\end{array}$ \\
\hline $\begin{array}{l}\text { Current situation } \\
\text { and the main } \\
\text { bottlenecks }\end{array}$ & $\begin{array}{l}\text { 1. Path dependency (tendency } \\
\text { to use gas and power for heat } \\
\text { generation) } \\
\text { 2. No legal mechanisms of } \\
\text { establishing of governmental } \\
\text { guarantees }\end{array}$ & $\begin{array}{l}\text { 1. Small amount of end-users } \\
\text { of power and heat in } \\
\text { "depressive" rural (approx. } \\
\text { 15\% of entire population of the } \\
\text { region) } \\
\text { 2. Secondary but not main } \\
\text { issue for state and regional } \\
\text { government }\end{array}$ \\
\hline
\end{tabular}

Developing of energy system on renewables is one of means to reach the goal of increasing sustainability of regional development. There are some undesirable side effects on this way.

For example, the absence of municipal and regional programs that must coordinate activity of different actors of the process may cause a haphazardly disbursement of local budget funds, discretization of technological approach. To avoid this it is necessary to develop feasible program and to monitor its realization. 
This is a leading role of government. A feasibility of program is determined both technical and economical possibilities. The first has to be done with the involvement of science and education for the purpose of development a regional technological basis and vendors of equipment. Here is important to avoid wrong or (and) expensive choice of technology or engine, or to avoid a fraud and fakes and widely use different forms of education [2]. Financing of all enforcements must be done. Usual government mechanisms of financial support are partial financing and making the environment attractive to investors and their funds for solving problems.

Actors mentioned above are summarized at the field "Interest-power" (fig. 1):

- Crowd: "Vendors" - suppliers of technologies and services; now vendors of renewables in Sverdlovsk region have no sufficient power of influence and interest for carrying their offers;

- Subjects: "Micro-scale consumers" and "Small and mid-scale consumers". They have correspondent interest but in practice they have no sufficient power to influence on any decisions in the field of renewables;

- Context setters: "Science", "Investors" can influence on decisions in the field of renewables but have no sufficient interest in dealing with renewables because of lack of subsidizing of R\&D or big expenses and investments in renewables;

- Players: "state and regional governments" - players who can decide and implement if they want.

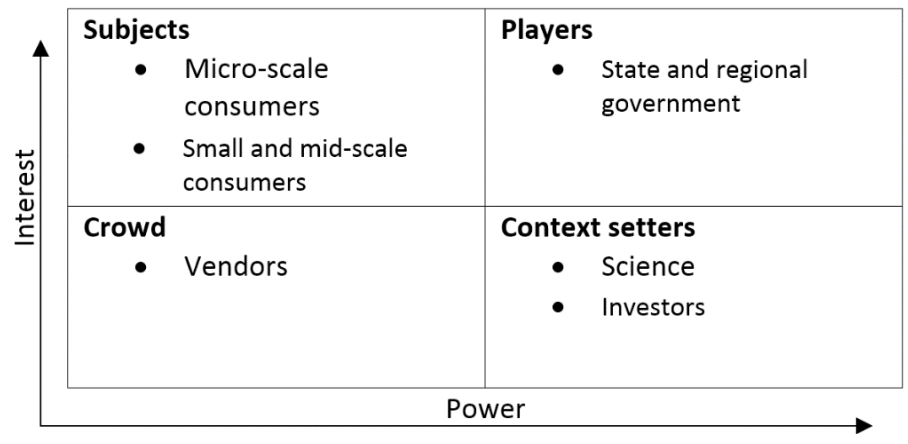

Figure 1: Actor's classification.

In figs 2 and 3, the "field of players" is shown. This is a triangle of components of the system of involving renewables in the fuel-energy balance. Three main components are in the basis (bottom of triangle): available technologies and services, regional or (and) state programs for developing renewable energy, and, of course, finance. Next line - quantitative indexes: quantity of successful introduction of micro-, small and medium scale renewables. In addition, on the top as the "sum" of them is the share of renewables in the fuel-energy balance. Upper triangle indicates the possible actors who has interest to the correspondent part of the system, bottom triangle - possible influenced actors. 


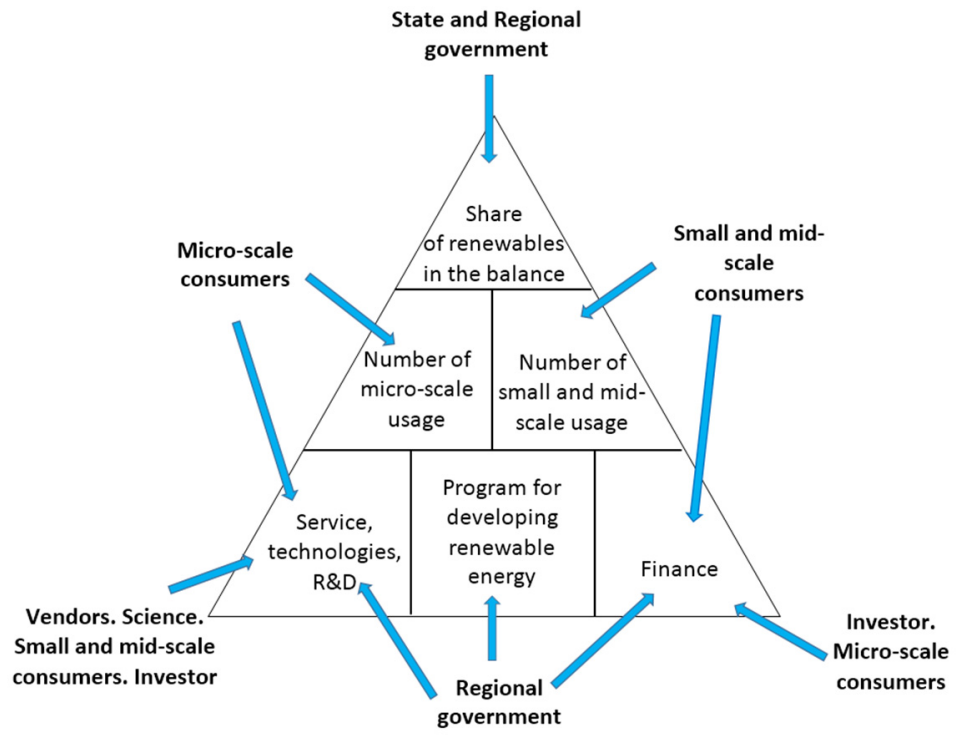

Figure 2: Interest in the system of involving renewables in the fuel-energy balance.

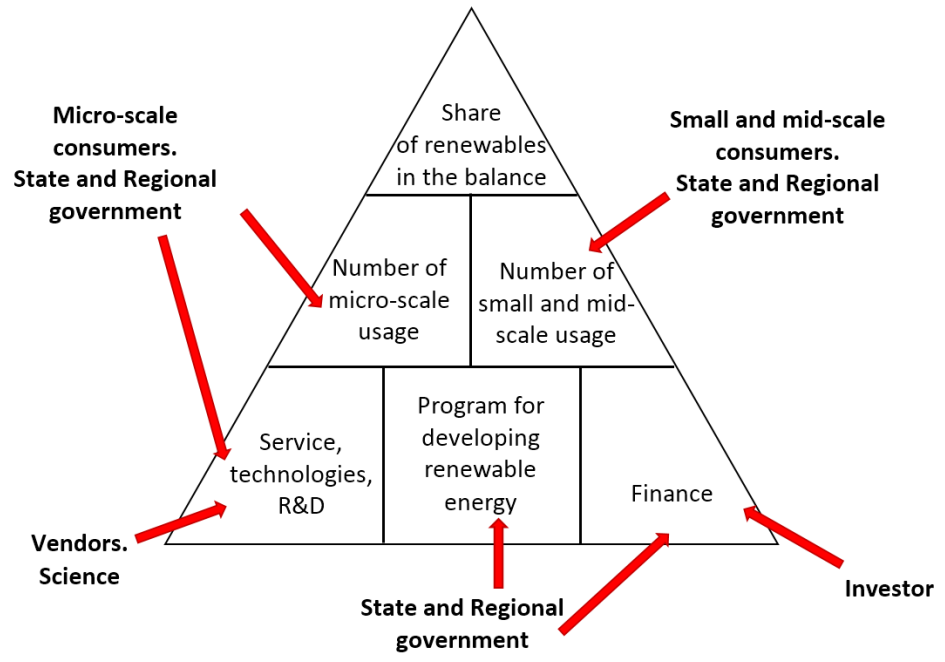

Figure 3: Influence in the system of involving renewables in the fuel-energy balance.

Players and context setters all in the basis of triangle and all of them are critical players (table 2). 
Table 2: Main features of players and context setters.

\begin{tabular}{|c|c|c|c|c|c|}
\hline Actor & Interests & \begin{tabular}{|c|} 
Existing \\
situation and gap
\end{tabular} & Causes & $\begin{array}{l}\text { Preferred } \\
\text { solutions }\end{array}$ & Own means \\
\hline \begin{tabular}{|l|} 
State and \\
regional \\
government
\end{tabular} & $\begin{array}{l}\text { Show care } \\
\text { about } \\
\text { improving } \\
\text { standards of } \\
\text { life of the } \\
\text { population }\end{array}$ & \begin{tabular}{|l|} 
Natural gas, \\
diesel, power \\
grid and coal \\
based \\
technologies are \\
too expensive \\
for "depressive" \\
rural
\end{tabular} & \begin{tabular}{|l|} 
Small \\
amount of \\
end users of \\
power and \\
heat in \\
"depressive" \\
rural \\
Path \\
dependency \\
\end{tabular} & \begin{tabular}{|l|} 
Order \\
development of \\
economically \\
viable technical \\
solutions and \\
monitor its \\
implementation \\
Attract investors
\end{tabular} & $\begin{array}{l}\begin{array}{l}\text { Subsidization } \\
\text { and stimulating } \\
\text { of R\&D }\end{array} \\
\text { Setting } \\
\text { preferences for } \\
\text { users and } \\
\text { producers of } \\
\text { renewable } \\
\text { energy }\end{array}$ \\
\hline Investors & $\begin{array}{l}\text { Make a } \\
\text { profit. } \\
\text { Get a } \\
\text { "'greener" } \\
\text { reputation }\end{array}$ & $\begin{array}{l}\text { There are no } \\
\text { guarantees, no } \\
\text { preferences, and } \\
\text { no developed } \\
\text { demand }\end{array}$ & \begin{tabular}{|l|} 
Secondary \\
but not main \\
issue for \\
state and \\
regional \\
government \\
Path \\
dependency \\
\end{tabular} & \begin{tabular}{|l|} 
Obtain state \\
guarantees, \\
including in the \\
form of \\
subsidies, \\
preferences and \\
proven \\
technology
\end{tabular} & $\begin{array}{l}\text { Finance } \\
\text { Networks }\end{array}$ \\
\hline $\begin{array}{l}\text { Science and } \\
\text { developers }\end{array}$ & $\begin{array}{l}\text { Increase } \\
\text { knowledge. } \\
\text { Obtain } \\
\text { financing }\end{array}$ & $\begin{array}{l}\text { Development on } \\
\text { a voluntary basis } \\
\text { without the } \\
\text { centralized order }\end{array}$ & \begin{tabular}{|l|} 
Secondary \\
but not main \\
issue for \\
state and \\
regional \\
government \\
\end{tabular} & $\begin{array}{l}\text { Work in the } \\
\text { framework of } \\
\text { long-term } \\
\text { research, } \\
\text { supported by the } \\
\text { state }\end{array}$ & Knowledge \\
\hline
\end{tabular}

\section{Desired behaviour of actors involved}

Desired behavior of actors, involved in the realization of potential program of developing renewable energy, in dynamic is shown at fig. 4.

The upper part of fig. 4 shows a moment of taking a program for developing renewable energy into operation (and period of operation). It lasts for 15 years, for example. It is the "impulse". Below are shown desired responses for two groups of end-users: a) "prosperous", b) "depressive" rural.

The first group of responses just starts with the start of the program but not finishes in the end of the program because of the number of individual cottages and cottage villages rises. The second group, in contrast to the first one, lasts while the program is in operation. Goals of the program have to include total equipping of rural by renewable energy sources. "Total" means the whole number of locations where there is a problem with energy supply and there are available renewables around them. 


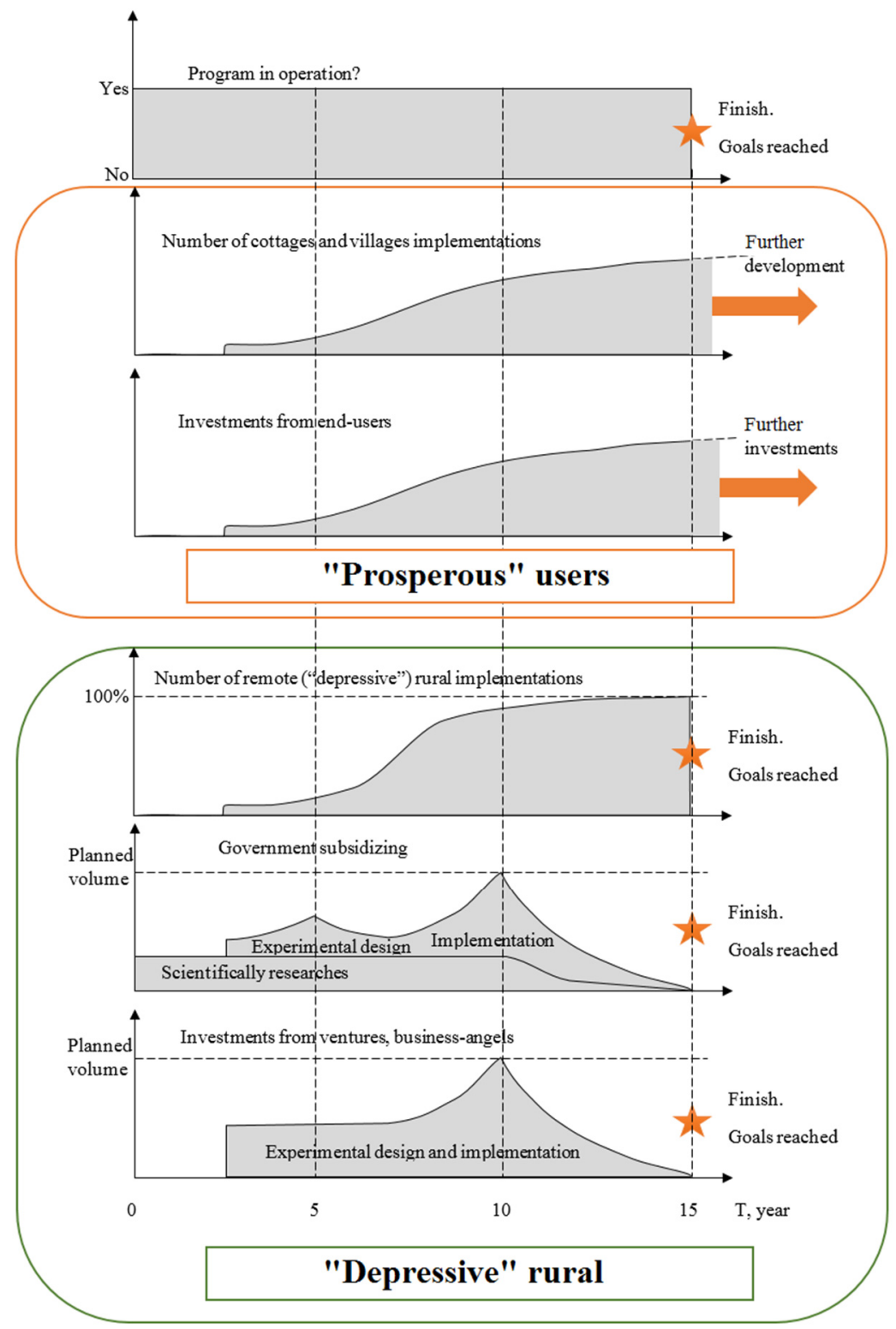

Figure 4: Desired behavior of actors.

Let's consider in this case that rural territories and their population are good subjects to test scientific researches on a wide range of issues [3]. So the main role in this case is dedicated to science and corresponding financial mechanisms (subsidizing, venture funds, business-angels). For example, from the first moment 
government should subsidize scientific researches. Other investors should involve in the deal from the moment of experimental design and further implementation of innovative items. When the program is finished and goals are reached, investors can demand partial or full return of investments and "greener" and "take care about social goals" reputation.

\section{Forcing the system}

One of indexes of successfulness of program of developing of renewable energy is the number of successful implementations of renewable energy in the region. Clipping of causal loop diagram of this index is shown at fig. 5. Here are viewed just the most explicit interconnections and influences. "Reinforcing" loop consists of two loops in accordance with two groups of end-users of renewable energy ("prosperous" and "depressive"). In the "balancing" loop one can see variable "Power, gas line affordability". These are some influential actors, not mentioned earlier, for example, gas and power suppliers. In case of "prosperous" locations like cottage villages, these actors have a significant interest and balancing influence.

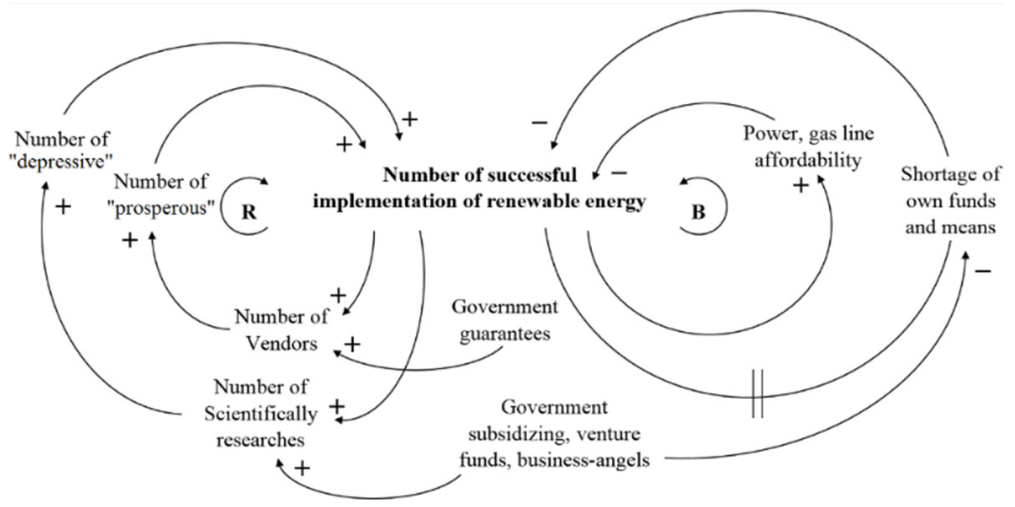

Figure 5: Clipping of causal loop diagram of "number of successful implementations of renewable energy" index of program of developing renewable energy.

As usual, the role of government in forcing both " $R$ " and " $B$ " loops is leading [4]. However, one more thing to force these loops is to use the approach of "inverse infrastructure". The "inverse" side of the field of players (fig. 1) in this case is "Subjects": micro-, small- and mid-scale consumers and vendors. The real thing that "Subjects" can do as elements of invers infrastructure is to start initiatively implement renewable energy. This step can eventually bring system into a new state by accumulating successful experience of introductions of renewables. It can influence on other actors, increasing the number of rural or cottages with renewables. In this case, "Subjects" becomes "Players" and actual "Players" (and "Context setters") has to make correspondent response. 
One more instrument for increasing the success of this step is a broadly covering in mass media and by advertising positive experience of implementation renewables and its benefit. Here appears a new actor - media.

\section{Conclusions}

1. Consumers of renewable energy may be classified depending on theirs prosperity level as "prosperous" and consumers from "depressive" remote rural; program of developing renewable energy must combine both types of consumers; dynamic of development and financial mechanisms differ in both cases.

2. Because of small amount of end-users of power and heat in "depressive" rural the problem of their energy supply is secondary for the government. It causes the absence of valuable attention, absence of guarantees and preferences, developed demand and centralized management. Investors cannot see the perspectives of development of regional renewable energy because there are no ways to return investments not to mention getting a profit. Basic preferred solutions for all parts involved are governmental guarantees, subsidies, setting preferences for users and producers of renewable energy, scientific researches within the long-term subsidizing programs.

3. One of possible steps to force the process of developing of renewable energy in the region in current conditions is to use "invers infrastructure" approach by stimulating the interest of "prosperous" consumers to increase number of introduction of renewable sources and to broadly cover in mass media and by advertising the positive experience of implementation renewables and its benefit.

\section{References}

[1] Smirnov, N. \& Menshikova, E., The Sverdlovsk Region: steps towards sustainable development and energy security, Proceedings of First International Conference on Energy Production and Management in the 21st Century, WIT Press. Vol. 1, pp. 1-8, 2014.

[2] Baldin, V. Yu., Danilov N.I., Khudyakova, G.I., The system of human resource development in energy saving in the Ural region, Proceedings of First International Conference On Energy Production and Management in the 21st Century, WIT Press. Vol. 2, pp. 1205-1214, 2014.

[3] Genon, G., Panepinto, D., Viggiano, F., Energy from biomass: the potentialities, environmental aspects and technology, Proceedings of First International Conference on Energy Production and Management in the 21st Century, WIT Press. Vol. 1, pp. 995-1006, 2014.

[4] Danilov, N.I., Silin, V.E., Dobrodey, V.I., Popov, V.E., Energy problems of the rational use of the economic potential of the region, Proceedings of First International Conference On Energy Production and Management in the 21st Century, WIT Press. Vol. 1, pp. 419-424, 2014. 